\title{
Oficina de Design com Foco na Terceira Idade de Belo Horizonte - MG
}

\author{
Design Workshop with Focus on the Third Age of Belo Horizonte - MG
}

PORTO, Camila Feldberg; Mestre; Universidade do Estado de Minas Gerais. feldbergc@gmail.com

REZENDE, Edson José Carpintero; Doutor; Universidade do Estado de Minas Gerais. edson.carpintero@gmail.com

\section{Resumo}

O aumento da população idosa torna relevante a discussão acerca dos direitos destes cidadãos. A pesquisa teve o objetivo de compreender quais são as principais leis que concernem aos idosos, entender como são feitas as políticas públicas e identificar se o design tem contribuições a fazer. Utilizou-se de uma revisão da literatura e de uma oficina com base no método duplo diamante, realizada com representes do poder público e da sociedade civil idosa de uma regional de Belo Horizonte - MG. Concluiu-se que o design pode contribuir tanto na organização das ideias surgidas em reuniões quanto em torná-las possíveis e mais eficientes.

Palavras Chave: política pública; idoso; design e duplo diamante.

\begin{abstract}
The increase of the older population makes relevant the discussion about citizens' rights. This research had the objectives: to understand which are the main laws related to older people, to understand how public policies are made, and to identify if the design study area has contributions to make. We made a literature review and a workshop based on the double diamond method. The workshop was done with people representing the public power and the older civil society from the West region of Belo Horizonte - MG. The conclusions were that design can contribute in organizing the ideas at meetings and make them more efficient.
\end{abstract}

Keywords: public policy; older people; design and double diamond. 


\section{Introdução}

O aumento da população idosa, que é atribuído a fatores como a redução da taxa de natalidade e avanços científicos na área da medicina, vem sendo assunto de debate para a sociedade e suas entidades governamentais. A realidade do envelhecimento populacional faz surgir questionamentos a respeito da qualidade de vida dos idosos no contexto urbano. Eles ainda enfrentam dificuldades para se manterem como membros ativos em suas comunidades, devido, principalmente, às restrições físicas decorrentes do envelhecimento. Por isso, e considerando que essa parcela populacional não tem todo o apoio social necessário para o seu bem-estar, é um papel social adequar as cidades para os idosos, especialmente no que tange às decisões políticas. Portanto, é preciso compreender como estas ocorrem.

Além disso, o design se mostra útil para a análise pretendida em função da sua inerente preocupação em entender a fundo os usuários dos projetos. Ele conta com metodologias e ferramentas que o auxiliam na identificação de problemas, de necessidades, de soluções criativas e chega a resultados inovadores que condizem com o que os usuários realmente precisam.

\section{Legislações que Concernem aos Idosos}

Na Constituição Federal de 1988 (CF-88) são feitas menções ao direito de envelhecimento dos cidadãos brasileiros. No artigo 5으, estabelece-se que todos são iguais perante a lei, não havendo distinções decorrentes de qualquer natureza, incluindo a idade. Nos artigos 229 e 230ㅇ há uma especificação à velhice no sentido de proteção: a família e o Estado têm o dever de amparar os idosos, assegurando seu bem-estar, dignidade e direito à vida (ARGÔLO, 2015; BRASIL, 1988). Entretanto, nota-se que no documento é dado aos idosos um caráter de objeto de proteção. Essa tutela especial ocorre devido a uma marginalização histórica sofrida por eles. Nesse sentido, surgiu a necessidade da criação do Estatuto do Idoso a fim garantir que os idosos sejam percebidos como indivíduos com direitos e autonomia (ARGÔLO, 2015; SOUZA, 2015).

O Estatuto do Idoso, disposto pela lei no 10.741/03 tem o intuito de regular os direitos das pessoas idosas, estabelecer obrigações ao poder público e dispor normas que discorrem a respeito dos direitos fundamentais dos idosos, de medidas de proteção, de políticas de atendimento, do acesso à justiça e de crimes relacionados (ARGÔLO, 2015; BRASIL, 2003). Estabelece, em seu artigo 2ㅇ, que o idoso tem todos os direitos fundamentais à pessoa humana e garante todas as oportunidades e facilidades para que este possa preservar a própria saúde física e mental e manter um aperfeiçoamento moral, intelectual e social. Esse estatuto também responsabiliza a família, a sociedade e o poder público por garantir condições fundamentais para a qualidade de vida do idoso (BRASIL, 2003; DIAS, 2013).

A promulgação do estatuto foi essencial para consolidar os direitos da população idosa, determinando a participação do Estado e da sociedade na manutenção do bem-estar da terceira idade. É a principal lei que defende os interesses da população idosa (ARGÔLO, 2015). Portanto, o Estado tem por obrigação, estabelecida nos artigos 8, 9 e 10 do Estatuto do Idoso, assegurar a liberdade, o respeito, a dignidade e o envelhecimento saudável, fazendo isto por meio de políticas públicas (BRASIL, 2003).

\section{Políticas Públicas}

As políticas públicas refletem o conjunto de ações e programas do Estado para a implantação de projetos governamentais que objetivam trazer melhorias para a sociedade e para 
os interesses públicos (FAÇANHA; LIMA, 2012; SOUZA, 2006). Elas são diretrizes, procedimentos e regras que irão direcionar as ações do Poder Público, bem como estabelecer as relações entre ele e a sociedade, a quem são voltadas as ações de mudanças (TORRENS, 2013). O momento de formulação das políticas públicas é aquele em que o governo cria programas que buscam estabelecer mudanças reais. Posteriormente, quando instituídos, eles passam a ser acompanhados e avaliados (SOUZA, 2006).

Para Gelinski e Seibel (2008) as políticas públicas são ações governamentais voltadas para a resolução de problemas de ordem pública e pode ter caráter social, relacionado à saúde, assistência, habitação e previdência dentre outros; caráter macroeconômico, referente a questões fiscais, monetárias ou industriais e podem ainda ter caráter diversificado, abrangendo tecnologias, cultura e agricultura, por exemplo. Rua (2009) explica que uma política pública não se restringe a apenas uma resolução, mas reflete várias iniciativas que levam a uma formulação estratégica de ações. Ela compreende diversas decisões políticas, que são tomadas pelo governo, embora possam ter berço em instituições privadas. Além disso, a política pública é multidisciplinar e requer contribuições sociais, políticas e econômicas, já que a sua implementação também repercute nessas áreas (SOUZA, 2006).

\subsection{Políticas Públicas no Brasil e o Controle Social}

A CF-88 permitiu o surgimento de conselhos gestores, o que estimulou a participação da população nas decisões de políticas públicas. Esses conselhos são espaços públicos considerados inovadores e tidos como fundamentais para a descentralização e a democratização das políticas públicas. Há conselhos nacionais, estaduais e municipais, todos contribuindo para que haja um canal de comunicação mais eficiente, no qual atores sociais participem no estabelecimento de mudanças e atuem na inserção de novas questões na agenda de políticas públicas. Os participantes dos conselhos são representantes do governo e da sociedade civil em igual número e os temas tratados são diversos, tais como: saúde, educação, moradia, transporte, cultura, meio ambiente, entre outros (MILANI, 2008; RAMOS et al., 2012; TATAGIBA, 2005).

Essa relação Estado-sociedade, na qual a segunda monitora as ações do primeiro, trata-se de um controle social. É por intermédio deste que a sociedade concretiza os seus direitos participativos, intervém na gestão pública, nos orçamentos e nas ações do Estado e orienta as decisões do governo. As políticas públicas, portanto, têm a sua efetividade como resultado do controle social, pois serão supervisionadas conforme a participação dos cidadãos a quem elas interessam (TAVARES; MARTINS; FIGUEIREDO, 2013).

Salienta-se que esse controle social não é realizado de forma estável, pois tende a sofrer mudanças conforme o modelo de administração pública em vigor e o perfil dos cidadãos participantes. Alguns canais de controle social são: comitês participativos, conselhos gestores, conferências, fóruns, dentre outros. Os participantes vão desde organizações privadas e públicas até o cidadão individual (MAGALHÃES; SOUZA, 2015).

Os costumes políticos, culturais e regionais interferem na participação da população nos conselhos gestores. Limitações socioeconômicas, simbólicas e políticas podem se mostrar como empecilhos para a participação, chegando a agravar a desigualdade política mesmo dentro de dispositivos participativos. O encorajamento à participação não é suficiente para garantir uma ação democrática eficiente, pois a quantidade de participantes não é tão relevante quanto a qualidade da participação de cada um (MILANI, 2008). 
Dessa forma, também merece atenção o perfil apresentado pelos conselheiros, ou seja, as pessoas que participam dos conselhos gestores, tanto da sociedade civil, quanto do governo. Uma vez que aqueles irão contribuir no processo de tomada de decisão, é importante que eles estejam cientes das necessidades dos indivíduos que irão representar (RAMOS et al., 2012). Milani (2008) entende que um dos desafios contemporâneos é o de estabelecer redes diversificadas de participação pública e de alta intensidade deliberativa.

Destaca-se a importância de haver espaços públicos que estimulem a participação, bem como a relevância de contar com a presença geral da sociedade (movimentos populares, sindicatos, indivíduos interessados, grupos e organizações públicas e privadas, dentre outros) no momento do controle social. Isto pode favorecer a transparência das decisões governamentais e ampliar a consciência dos interesses de uma maior parcela da sociedade, representando-a de maneira mais eficiente e legítima (MALAQUIAS et al., 2016; PAULA et al., 2015).

\subsection{Conselhos de Políticas Públicas de Belo Horizonte}

Milani (2008) afirma que Belo Horizonte apresenta uma ação pública local de alta intensidade, dada a sua ampla diversidade de atores locais no processo decisório. No sítio eletrônico da prefeitura de Belo Horizonte ${ }^{1}$ é possível consultar os conselhos existentes na cidade. Tratam-se de espaços públicos de deliberação, que contam com a participação de representantes da sociedade e do governo, destinados a promover o debate, com o objetivo de alcançar um consenso, no que se refere à formulação de políticas públicas e do acompanhamento das já existentes. Em uma rápida consulta, identifica-se a existência de 24 conselhos que abordam questões diversas, tais como mobilidade urbana, terceira idade, assistência social, entre outras. Especificamente o Conselho Municipal do Idoso (CMI) de Belo Horizonte conta com a participação de 68 pessoas: 34 representantes do poder público, sendo 17 titulares e 17 suplentes, e 34 da sociedade civil, também 17 titulares e 17 suplentes $^{2}$. O CMI é um canal de suma importância para levar as questões concernentes aos interesses dos idosos para o patamar de políticas públicas.

\section{Design Contribuindo para Políticas Públicas}

O design pode beneficiar o desenvolvimento de serviços públicos por ser uma disciplina que estuda a real experiência dos usuários de um determinado serviço e por se preocupar em como melhorá-lo e torná-lo mais barato. O design também auxilia na tomada de decisões em situações complexas ao simulá-las, por meio de protótipos e mock-ups, para que sejam previamente testadas. Os métodos de design promovem o engajamento público, com a consulta e colaboração dos usuários dos serviços, ao invés da imposição do serviço para eles. Assim, garantem que as pessoas estejam mais predispostas a aceitar um novo serviço (DESIGN COMISSION, 2013).

Kingsmill e Quirk (2013) acreditam que o mau desenvolvimento de serviços públicos geram muitos gastos para um país e que uma boa prática de design pode proporcionar serviços mais relevantes para as necessidades em questão. Acrescenta-se que ter o apoio da população favorece a redução de gastos, já que a sua oposição poderia causar descontentamento e necessidade de realizar novos projetos (DESIGN COMMISSION, 2013).

\footnotetext{
1 Para encontrar o colegiado. Disponível em: <http://colegiados.pbh.gov.br/sgc/iFramePortalPbh.php?tc=268> Acesso em 21 de novembro de 2016.

${ }^{2}$ Colegiados: conselhos de políticas públicas. Disponível em: $<$ http://portalpbh.pbh.gov.br/pbh/ecp/comunidade.do?evento=portlet\&pld

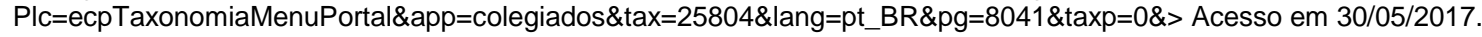


Alguns serviços públicos podem ser co-criados ou co-produzidos ao combinar a participação dos agentes do serviço público e de pessoas voluntárias, normalmente usuárias, que buscam melhorias ou aumento no número de serviços que utilizam. Essa cocriação é instigada pela facilidade em participar e pela importância que é dada ao serviço. Assim, serviços contínuos tendem a ter maior participação, porque impactam os usuários por mais tempo. Essa participação pode ser individual ou coletiva e, inclusive, contar com recursos do terceiro setor (PESTOFF, 2012).

Contudo, o uso do design no setor público passa por dificuldades. O pouco conhecimento sobre área do design é uma delas, pois dificulta a inclusão dos designers nesse setor. O próprio nome "design" é pouco compreendido e não está claro o quanto da comunidade de designers está preparada para encarar os desafios públicos e sociais. A falta de regulamentação torna duvidoso o impacto e a qualidade que as soluções podem ter. Poucas soluções bem sucedidas foram documentadas, tornando mais difícil mensurar os benefícios que o design pode fornecer. Ainda assim, acredita-se que incluir os usuários desde o começo na decisão de uma política pública com a participação do designer signifique tornar o serviço mais eficiente (DESIGN COMISSION, 2013).

Bryson et al. (2012) pesquisaram 250 artigos científicos e identificaram a possibilidade de desenvolver processos de participação pública por meio do projeto de atividades especialmente voltadas para esse fim. Valorizou-se a capacidade de integrar os usuários e as partes interessadas na realização de protótipos diversos, até que se chegasse à melhor solução. Portanto, o design pode apontar soluções que contem com a ação participativa direta do público idoso.

Com um design participativo é possível desenvolver alternativas eficientes e mais condizentes com o público em questão. Essa abordagem do design é uma forma de inserir as pessoas no processo projetual; é um ato de criação participativa que busca orientar e inspirar a geração de ideias e de conceitos. Ao dar voz às comunidades, usuários e famílias e ao se incorporarem as informações fornecidas por eles e seus feedbacks, tem-se uma noção maior das suas reais necessidades (TORRES, 2015). Além disso, o envolvimento de atores múltiplos é importante para a integração de valores e de necessidades variadas em um dado contexto (VELASQUES, FRANZATO, DEL GAUDIO, 2015). Portanto, entende-se que a participação da população idosa e da comunidade, com a moderação de um designer, resulte em benefícios para as ações de controle social.

\section{Metodologia}

Esse trabalho é um recorte de uma pesquisa de mestrado. Nesta foi feito um diagnóstico sobre o quanto uma região de Belo Horizonte pode ser considerada amiga do idoso. Para tal, utilizou-se o Guia Global da Cidade Amiga do Idoso, desenvolvido pela OMS. Nele constam diretrizes de pesquisa e um checklist para o acompanhamento da investigação. Foram utilizados grupos focais para a coleta das informações. Posteriormente as informações foram analisadas e os resultados desse diagnóstico foram utilizados para realizar uma oficina participativa com representantes do poder público e da sociedade civil idosa de uma região de Belo Horizonte.

\subsection{Campo e contexto de estudo}

O estudo foi conduzido na cidade de Belo Horizonte - MG, que apresenta nove subdivisões gerenciais, nomeadas de Regiões Administrativas (RA) ou de regionais. São elas: Barreiro, Centrosul, Leste, Nordeste, Noroeste, Norte, Oeste, Pampulha e Venda Nova. O campo e o contexto de estudo desta investigação corresponde à RA Oeste, escolha feita por conveniência. 
Nessa RA há um grupo de trabalho (GT) voltado para as questões dos idosos. Ele é composto pelos coordenadores dos grupos de convivência de idosos, localizados na regional, e também conta com a participação de funcionários da Secretaria Administrativa Regional Municipal Oeste (SARMO). A partir desse grupo, foram eleitos dois idosos para representar a RA Oeste no Conselho Municipal do Idoso e há, também, uma representante do poder público oriunda dessa regional (FIG 1). Assim, é possível levar os interesses da RA Oeste a deliberações municipais.

Figura 1 - Participantes do Conselho Municipal do Idoso oriundos da Regional Oeste de Belo Horizonte.

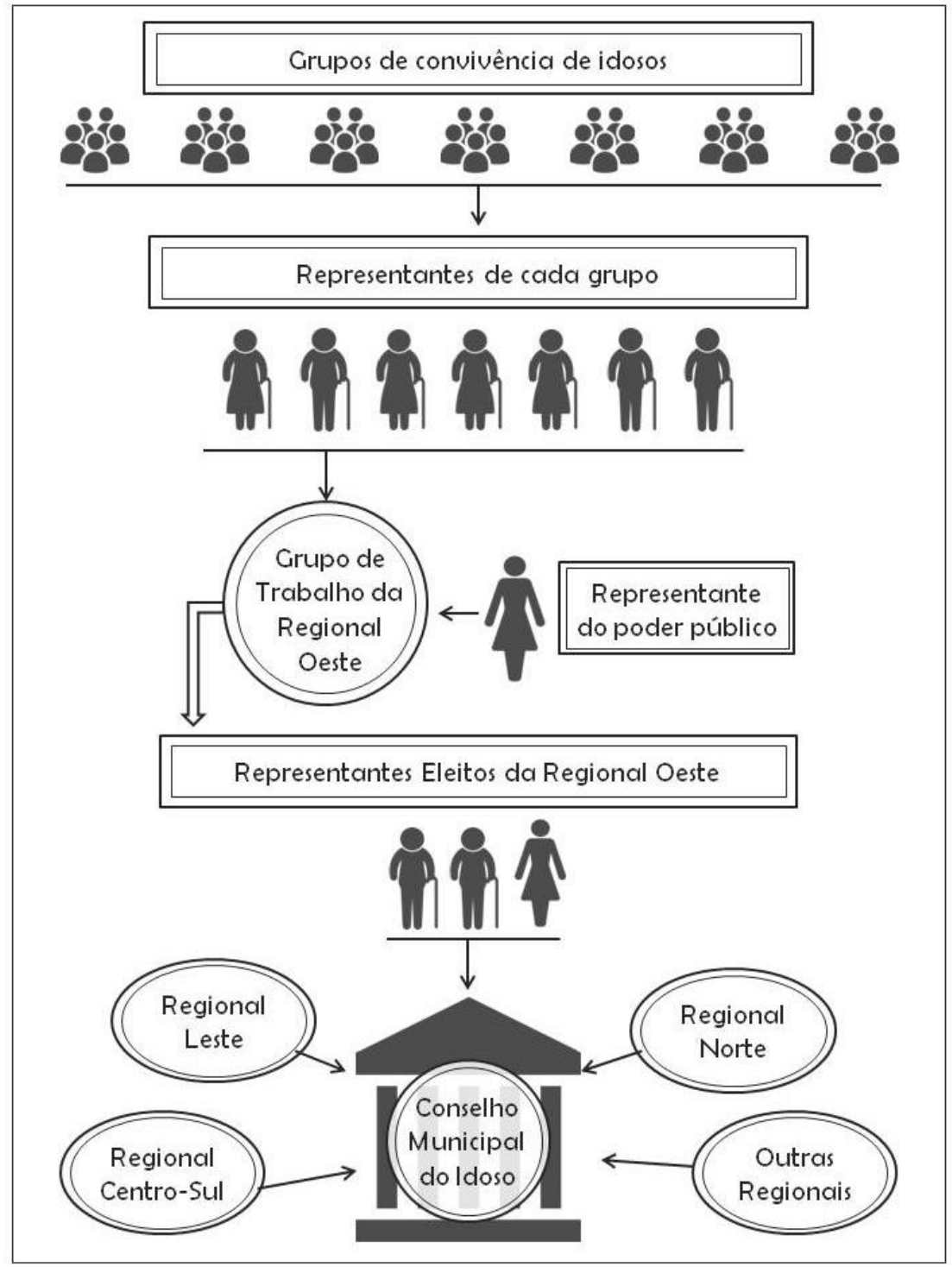

Fonte: Autores

As reuniões do GT ocorrem mensalmente e dela participam um número variado de pessoas, mas são regulares mais de 20 idosos. Em casos de ausência frequente, o poder público busca saber o motivo da falta, encoraja a participação pública e estimula o empoderamento da pessoa idosa. Entretanto isso não necessariamente ocorre nas demais regionais. Portanto, o GT é uma instância de controle social, bem como os conselhos municipais, pois a sociedade civil atua em conjunto com o poder público para deliberar decisões para esta ${ }^{3}$.

\footnotetext{
${ }^{3}$ Informação verbal adquirida ao longo da participação dos pesquisadores nos GT em 2016 e 2017.
} 


\subsection{Oficina Participativa}

As oficinas oferecem um momento para a construção de um conhecimento, com embasamento teórico, através da ação. Elas possibilitam aos participantes se apropriarem, construírem e produzirem conhecimentos teóricos e práticos através de ação e reflexão. 0 objetivo das oficinas é articular conceitos e pressupostos com ações concretas, vivenciadas pelos participantes e proporcionar vivências e execuções de tarefas em equipe, gerando uma construção de saberes coletivamente (PAVIANI; FONTANA, 2009).

Das diferentes metodologias de design, optou-se por utilizar, na oficina, o método duplo diamante, pois se acredita ser um dos mais fáceis de comunicar para indivíduos que não tenham nenhum contato com a área do design. A oficina garantiu um momento de compartilhamento do método e deu oportunidade para que os participantes aplicassem-no com o objetivo de não apenas esboçar uma solução, mas de conhecer uma nova forma de lidar com os problemas, diferente do que eles possivelmente estariam acostumados.

O duplo diamante se trata de um diagrama que toma o formato do seu nome: dois losangos, que lembram diamantes. Organizado em quatro fases, esse método tem como proposta principal as ações de divergir e convergir, que permeiam as ações de designers durante um projeto. As duas primeiras fases, descobrir e definir, estão no primeiro diamante, que corresponde ao momento de problematização. As outras duas, desenvolver e refinar, estão no segundo, são referentes ao momento de solução (FIG. 2) (DESIGN COUNCIL, 2007; POZATTI; BERNARDES; VAN DER LINDEN, 2016).

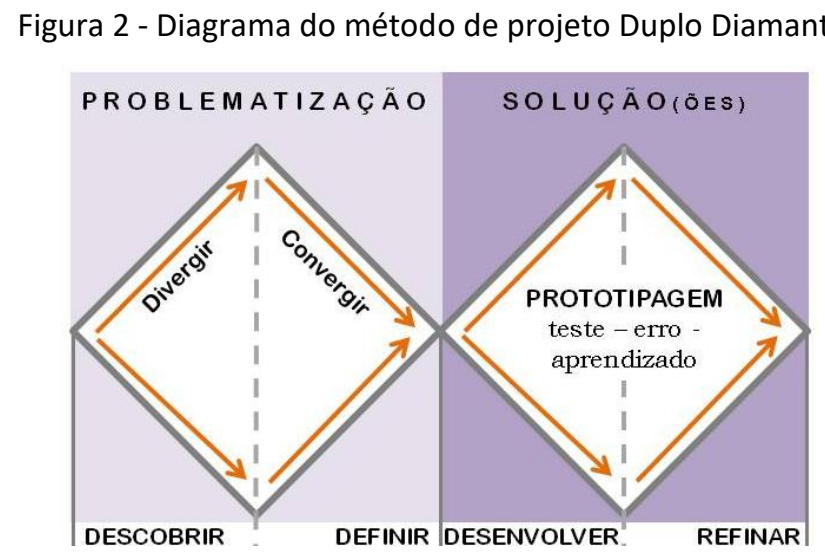

Fonte: Adaptado de Design Council, 2007.

A etapa "descobrir" parte de um problema inicial, ou oportunidade, geralmente identificado após uma pesquisa anterior ao uso do método. Os envolvidos devem divergir seus pensamentos, fazendo perguntas e gerando hipóteses. Na fase "definir", convergem-se as ideias para analisar e sintetizar o que foi discutido na etapa anterior, a fim de definir o problema que será de fato abordado e começar a identificar formas de solucioná-lo. Já no segundo diamante, a etapa "desenvolver" é o momento em que os participantes divergem sobre ideias de soluções para o problema levantado na fase anterior. Utilizam-se frequentemente técnicas de criatividade, como o brainstorming, ou seja, tempestade de ideias, que favorece o surgimento de ideias diferenciadas sem julgamento. A última fase, "refinar", é quando os envolvidos decidem qual é a melhor solução para o problema identificado previamente. Incluem-se, aqui, formas de receber retorno a respeito da solução (DESIGN COUNCIL, 2007). 


\subsection{Etapas do método.}

Foram convidadas oito pessoas para participar da oficina: três do poder público e cinco da sociedade civil. Entretanto, apenas cinco puderam comparecer no dia e horário agendados. A oficina contou com a participação de três representantes do poder público, vinculados à SARMO, e dois idosos, representantes da sociedade civil no CMI e eleitos pelos idosos participantes do Grupo de Trabalho dos Idosos da RA Oeste, além da moderadora, que é graduada em Design de Produto. Apesar de apenas dois participantes serem da sociedade civil e idosos, os demais são pessoas altamente engajadas nas questões da terceira idade e contribuem ativamente, na prefeitura, com a defesa dos direitos da população idosa há mais de 10 anos.

A oficina teve duração de 145 minutos. Ela foi iniciada com a entrega de pranchas gráficas, que continham os resultados de um diagnóstico sobre as opiniões dos idosos da RA Oeste de Belo Horizonte, previamente realizado. Naquelas, constavam os principais pontos positivos, negativos e desejos dos idosos da regional, a respeito dos oito tópicos do Guia Global da Cidade Amiga do Idoso, que são: (1) espaços abertos e prédios; (2) transporte; (3) moradia; (4) participação social; (5) respeito e inclusão social; (6) participação cívica e emprego; (7) informação e comunicação e (8) apoio comunitário e serviços de saúde. A figura 3 resume as etapas da oficina.

Figura 3 - Etapas da oficina com os representantes da Regional Oeste.

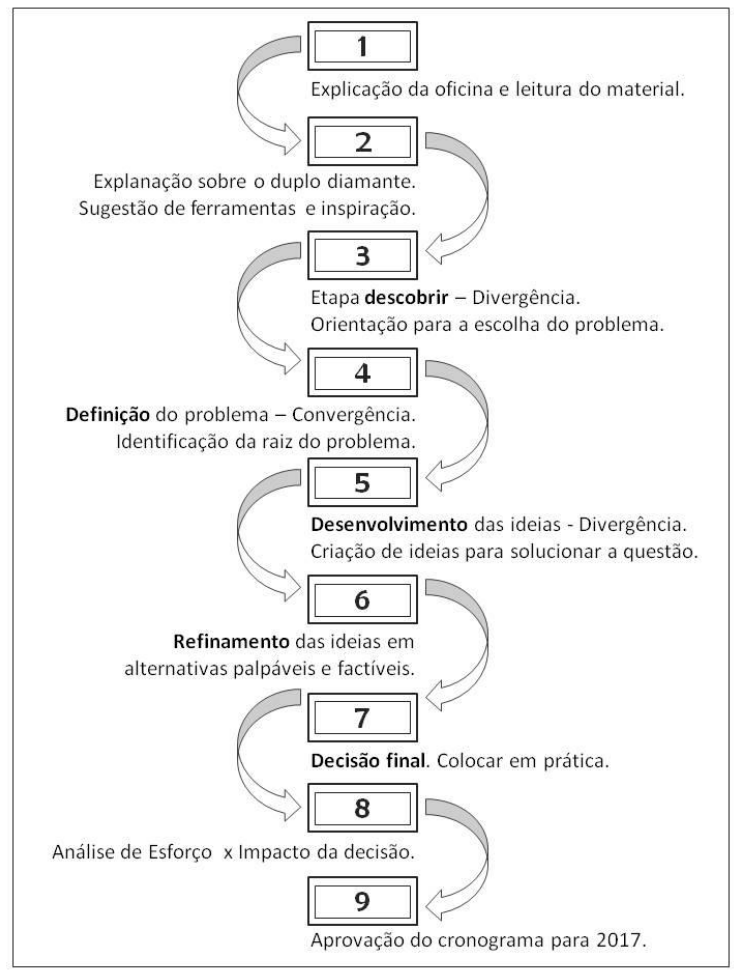

Fonte: Autores.

Na primeira etapa, explicou-se o que seria feito no encontro e as pranchas com os resultados do diagnóstico foram entregues para que fossem lidas e analisadas e para que os participantes refletissem sobre o conteúdo. Na segunda etapa, explicou-se sobre o método duplo diamante. Também foram sugeridas duas ferramentas a serem utilizadas nas etapas de "definir" e "refinar". A primeira ferramenta foi os "Cinco porquês", que é utilizada para identificar a raiz e os sintomas de um problema, perguntando-se "por quê?" cinco vezes. Após o seu uso, é possível identificar as verdadeiras causas de um determinado problema, que poderiam estar camufladas 
por situações mais óbvias (CAMPOS, 2016). A segunda foi a Matriz Esforço x Impacto, que ajuda a priorizar as soluções que gerarem maior impacto positivo com o menor esforço despendido (FURUKAWA; CUNHA; PEDREIRA, 2016). Foi oferecida, ainda, uma inspiração: um estudo sobre o estado de São Paulo, que tem um programa para torná-lo amigo do idoso.

Nas terceira e quarta etapas, os participantes divergiram e convergiram a respeito do problema a ser tratado. Nas quinta e sexta etapas, eles, mais uma vez, divergiram e convergiram quanto à solução. Por fim, nas três últimas etapas, eles tomaram as decisões finais.

A oficina foi gravada e transcrita na íntegra. A transcrição foi lida exaustivamente e as informações relevantes foram organizadas dentro das fases da metodologia duplo diamante. Em seguida a experiência foi relatada na forma escrita.

Esse projeto foi submetido à apreciação do Comitê de Ética em Pesquisa da Universidade do Estado de Minas Gerais (UEMG), em 25 de novembro de 2015. O projeto seguiu os preceitos da resolução 466/2012 e da 510/16 e foi aprovado em 21 de dezembro de 2015, sob o registro CAAE no 51599415.7.0000.5525.

\section{Resultados}

\subsection{Oficina e método duplo diamante}

Enquanto os participantes liam os pontos negativos, positivos e de desejo dos idosos, nas pranchas entregues, já começavam a discutir sobre eles. Os integrantes do poder público validavam o que estava escrito, confirmando que já tinham ouvido os idosos fazerem aqueles comentários. Também perguntavam aos participantes idosos a opinião deles e falavam de abordagens feitas em outros lugares, sugerindo que pudessem ser aplicadas nas questões apresentadas. Aos poucos foram surgindo ideias sobre os tópicos.

Esse ponto aqui, do semáforo, é um ponto que a gente sempre discutiu, né? O tempo do semáforo é menor que o tempo de reação do idoso (...) Um trabalho (...) que a BH Trans fez (...) com a população, é um trabalho desse pessoal vestido de palhaço (...) nos pontos finais pra fazer uma brincadeira com os motoristas $(\mathrm{P} 1)^{4}$.

Nesse momento, explicou-se como se dá o método do duplo diamante. Chamou-se a atenção para a raiz e os sintomas dos problemas e explanou-se como identificá-los. Também foi exposta a importância de criar ideias e alternativas sem julgamentos e como avaliar as melhores soluções conforme um gráfico de esforço $x$ impacto. Sugeriu-se que fosse respondida a pergunta: "qual o caminho para tornar isso possível"? Como inspiração, foram entregues documentos a respeito do programa "São Paulo amigo do idoso".

Todos ficaram atentos durante toda a explanação e tiraram eventuais dúvidas nesse momento. Em seguida, um dos participantes sugeriu que o foco inicial fosse dado para o tema de transporte: "olha, eu tinha uma proposta: a gente começar lá da parte do transporte e depois a gente pegar essas outras que não têm tanto impacto com a nossa prática aqui" (P2). Os demais integrantes concordaram.

Os participantes começaram a conversar sobre as possibilidades de resolver as questões apontadas na prancha de transporte. Os representantes do poder público indagaram os idosos

\footnotetext{
${ }^{4}$ Todas as falas, aqui, são oriundas de participantes do grupo que compôs a oficina. As pessoas são identificadas com a letra $\mathrm{P}$ em número crescente, conforme aparecem no texto. Não foram apresentadas falas de todas as pessoas.
} 
quanto aos problemas relacionados a esse tópico. Nesse momento, a moderadora interrompeu, justificando que os problemas já foram identificados e apresentados na prancha e que seria necessário evitar dispersões e focar nas técnicas para resolução.

Então, todos conversaram sobre o reduzido respeito dos motoristas de ônibus com os idosos e sobre soluções para isso. Falaram de trabalhos já propostos, inclusive pela BH Trans, empresa de trânsito de Belo Horizonte, e decidiram que o caminho para trazer melhorias é a conscientização. Aqui, a moderadora sugeriu que eles tentassem determinar a raiz e os sintomas do problema antes de estabelecer a conscientização como solução. Ela instruiu que fossem feitas perguntas "por quê?" seguidamente, até que se encontrasse a raiz.

a) Por que os motoristas não respeitam os idosos? Estresse.

b) Por que os motoristas estão estressados? Salário, violência, trabalhar com tempo prédeterminado, ser multado caso não cumpra o tempo, má educação e grosseria de passageiros, inclusive de idosos: "porque muitos usuários fazem acontecer esse estresse no motorista"(P3). A qualidade de vida profissional do motorista é prejudicada.

Um dos representantes do poder público é mais objetivo e prefere focar na conscientização, por ser uma alternativa mais viável.

\begin{abstract}
Agora, eu ainda acho que as ações junto com a gerência de ação de conscientização, elas são mais viáveis do que a gente pensar em toda uma reestruturação pra gente alcançar uma melhoria na qualidade de vida do motorista, impactos financeiros, dentre outras ordens. Acho que a gente pensar em soluções por esse lado é caminhar até pra um local mais distante da gente conseguir gerar um impacto. Já as ações de conscientização, (...) de trabalhar, talvez, uma ação com a gerência de educação no trânsito, que é a GEDUC, com o Mobiliza SUAS, (...), de conscientização... (P2).
\end{abstract}

A partir dessa fala outras ideias foram surgindo, como: levar a questão para o CMI fiscalizar; buscar uma emissora de televisão para levar a queixa e fazer uma divulgação mais pesada do problema e utilizar os jornais do ônibus e a televisão do ônibus para divulgar peças publicitárias de conscientização. Recordou-se que este tipo de campanha deve ser feito pela $\mathrm{BH}$ Trans e que já havia sido uma proposta da empresa, através da Gerência de Educação para o Trânsito (GEDUC). Enquanto os participantes conversavam a respeito de canais de divulgação e conscientização, um dos integrantes do poder público começou a refletir sobre o assunto de forma a torná-lo uma discussão ativa no meio público. Com base nessas reflexões, compartilhadas com o grupo, as primeiras ideias começaram a tomar forma, assim como alternativas para viabilizá-las. Simultaneamente, a moderadora as registrava em post-its e deixava na mesa de forma visível a todos.

1a ideia: voltar as soluções para trabalhos de conscientização e educação de motoristas e de usuários do ônibus.

2a ideia: questionar a GEDUC sobre o que já foi feito via fórum deliberativo.

3a ideia: colocar o assunto em pauta para o cronograma de 2017.

Em seguida, os participantes conversaram sobre formas de concretizar o trabalho de conscientização. Voltaram a falar sobre campanhas publicitárias na televisão e buscaram entender qual seria o caminho para isso. Identificaram o que poderia ser realizado pela própria GEDUC, mas cobrado pela coordenadoria do idoso, pelo conselho do idoso e pelo movimento pró-idoso. Além 
disso, pensaram em quem convidar para comparecer ao fórum deliberativo.

As dificuldades também foram surgindo. A primeira delas foi quanto à troca de prefeito, que geraria mudanças no âmbito público e incertezas para o início de 2017. A segunda foi uma preocupação de avisar com antecedência os possíveis convidados do fórum, como a GEDUC, para que pudessem se preparar para o evento e terem as respostas para a população.

Outras conversas foram se desenvolvendo. Surgiram sugestões de: fazer um abaixoassinado, para que a proposta de conscientização ganhasse mais força; incluir tudo o que estava sendo discutido no cronograma de 2017 e fazer um "pós-fórum" na forma de uma audiência pública, convidando vereadores, no intuito de pressioná-los para exigirem o trabalho de conscientização.

\subsection{Decisão final}

Após todas as reflexões e discussões, os participantes redigiram as decisões tomadas e as incluíram no cronograma de 2017, que foi, posteriormente, discutido no GT e aprovado. As decisões foram:

1. Dia 06/02/2017: comissão para determinar o que será cobrado da GEDUC, por exemplo, trabalhos de conscientização dos motoristas.

2. Dia 07/02/2017: no primeiro GT do ano, propor abaixo-assinado, para fortalecer a exigência.

3. Dia 10/03/2017: dialogar com a GEDUC, requerer o cronograma de suas ações e cobrar os resultados do trabalho de conscientização (que já havia sido proposto anteriormente), para que pudessem ser levados ao fórum do dia 21/06/2017.

4. Dia 21/06/2017: realização do fórum deliberativo com a participação de um representante do CMI, da BH Trans, do Movimento Pró-Idoso e dos pesquisadores (para apresentarem os resultados da pesquisa).

5. Solicitação de uma audiência pública com um vereador. Para a audiência, convidar novamente representantes do CMI, da BH Trans, do Movimento Pró-Idoso, da coordenadoria do idoso e do Sindicato dos Motoristas, no sentido de abordar as questões de qualidade de vida para os profissionais.

6. Cobrar e fiscalizar as ações.

\subsection{Confronto da decisão final com os problemas (esforço x impacto)}

Os participantes retornaram à prancha pra visualizar, novamente, os problemas pontuados pela moderadora. Identificaram que a maioria deles poderia ser contemplada pelas decisões que foram tomadas durante a oficina. Excetuando-se o problema de acessibilidade, pois ele é estrutural, de alto custo e longo prazo, e os problemas de segurança pública, pois fogem do âmbito de atuação dos envolvidos.

Concluíram que, apesar de o foco de solução ter sido a conscientização de motoristas e passageiros, as questões como valor do táxi e itinerário dos ônibus também poderiam ser atendidas através do diálogo com a BH Trans, que foi estruturado nas decisões da mesa.

Posteriormente, o cronograma proposto foi aprovado pelos participantes do GT dos idosos da regional Oeste, no dia seguinte ao encontro da oficina. Entretanto, a previsão de dificuldades 
com a troca de prefeito se concretizou e, até o final de 2017, não foi possível realizar o fórum com tema transporte.

\section{Discussão}

Observou-se que no dia da oficina os participantes conseguiram utilizar o método do duplo diamante para tomar decisões de uma forma dinâmica e rápida. Contudo, não é possível consolidar o método sem utilizá-lo com frequência. Por isso, levar o design para os profissionais do poder público, estimulando-os a pensar de maneira holística, centrada nos usuários e criativamente, pode ser uma boa sugestão. O processo dos participantes foi interessante, porque conseguiram evitar pré-julgamentos de ideias e mantiveram a objetividade. As soluções de conscientização e sensibilização foram as primeiras sugestões, mas outras também surgiram e os próprios participantes conseguiram determinar motivos para manter a ideia inicial. 0 caminho que levou às decisões finais só foi possível com o conhecimento dos integrantes do poder público, especificamente, de como ocorre o controle social e como realizá-lo de maneira benéfica para o público interessado, ou seja, os idosos. Essa parceria, entre poder público e sociedade civil se mostrou muito presente e forte no GT dos idosos da RA Oeste.

Entretanto, entende-se que a composição da oficina possa ter interferido nos resultados alcançados. Esta contou com um maior número de representantes do poder público (três pessoas) do que dos idosos (duas pessoas). Notou-se que os representantes do poder público se esforçaram para pensar como um idoso pensaria nas circunstâncias mencionadas. Contudo, devese ter em vista que eles não são idosos. Embora exista um relacionamento próximo à amizade entre os indivíduos participantes, a voz dos idosos ficou em segundo plano por receio de fazer alguns comentários que pudessem ser considerados pouco construtivos. Esse receio realça a necessidade de empoderamento dessas pessoas, no sentido de Ihes dar segurança e confiança quanto às suas opiniões e de lhes garantir que são de suma importância para o desenvolvimento de soluções para si mesmos e para os idosos do futuro.

A partir dos resultados da oficina com o uso do duplo diamante, também foi possível perceber que esse método pode ser utilizado para criar desdobramentos de outras divergências e convergências. Dessa forma, identificou-se que os resultados dos momentos contemplados na oficina podem corresponder a um duplo diamante inserido em um diamante maior, o que indica que o cronograma para 2017 (solução alcançada após a oficina) pode ser o início de uma nova fase de desenvolvimento de soluções ou de descoberta de novos problemas.

Portanto, acredita-se que, de fato, o design pode agregar muito no âmbito estratégico das ações públicas, com seus métodos, suas ferramentas, técnicas centradas nos usuários, abertura para o diálogo e trabalho inter e multidisciplinar. Corroborando com a ideia do Design Comission (2013), incentiva-se que os designers estejam cada vez mais presentes na vida política da cidade.

\section{Considerações finais}

A aplicação do método duplo diamante em um grupo politicamente engajado trouxe resultados interessantes quanto ao processo de design, mais do que em relação às soluções adquiridas. Esses métodos de design se mostraram relevantes no sentido de aprimorar os processos de tomadas de decisão, tornando-os mais eficientes. Assim, utilizar o design no cotidiano do desenvolvimento de agendas e, inclusive, de políticas públicas, pode ser uma atitude 
estratégica para o poder público. Vale ressaltar que, além de propor soluções, o designer tem muito a contribuir na articulação de diferentes profissionais e ideias com o objetivo de trazer melhorias para a cidade.

Sugere-se que estudos futuros se aprofundem no uso do design na esfera política, levandoo a esse ambiente com maior frequência, a fim de compreender a fundo os resultados e benefícios dessa relação.

\section{Referências}

ARGÔLO, D. E. A legitimação da legislação simbólica no ordenamento jurídico brasileiro: o caso do estatuto do idoso. 2015, 93 f. Dissertação (Mestrado em Direito) - Faculdade de Direito, Universidade Federal da Bahia, Salvador.

BRASIL. Constituição, $1988 . \quad$ Disponível em: < http://www.planalto.gov.br/ccivil_03/constituicao/constituicaocompilado.htm> Acesso em 21 de novembro de 2016.

BRASIL. Lei no 10.741, de 1으 de outubro de 2003. Estatuto do Idoso. Disponível em: <http://www.planalto.gov.br/ccivil_03/leis/2003/L10.741.htm\#art53> Acesso em 21 de novembro de 2016.

BRYSON, J. M. et al. Designing Public Participation Processes. Public Administration Review, v. 73, iss. 1, p. 23-34, 2012. Disponível em: <http://onlinelibrary.wiley.com/doi/10.1111/j.15406210.2012.02678.x/abstract> Acesso em maio de 2016.

CAMPOS, A. L. P. Utilização de ferramentas da qualidade para proposição de melhorias no processo de uma aciaria de grande porte com vistas à redução de ocorrências de clogging. 2016. 57 f. Monografia (Graduação em Engenharia de Produção) - Instituto de Ciências Exatas e Aplicadas, Universidade Federal de Ouro Preto, João Monlevade, 2016.

DESIGN COMISSION. Restarting Britain 2: design and public services. Londres: Policy Connect, 2013. 64p.

DESIGN COUNCIL. A study of the process. Londres: WC2E, 2007. 144 p.

DIAS, E. F. O envelhecimento populacional e o direito à saúde da pessoa idosa. Revista Jurídica Direito, Sociedade e Justiça, Dourados, v. 1, n. 1, p. 1-14, 2013.

FAÇANHA, L. F. C.; LIMA, S. O. O ministério público dos estados e a implementação das políticas públicas sociais: um caminho para o enfrentamento à pobreza, à desigualdade e à exclusão social. In: CIRCUITO DE DEBATES ACADÊMICOS, 1, 2011. Anais... Brasília, 2012. Disponível em: <http://www.ipea.gov.br/code2011/chamada2011/pdf/area2/area2-artigo25.pdf>. Acesso em 23/08/2016.

FURUKAWA, P. O.; CUNHA, I. C. K. O.; PEDREIRA, M. L. G. Avaliação de ações ecologicamente sustentáveis no processo de medicação. Revista Brasileira de Enfermagem. Brasília, v. 69, n. 1, p. 16-22, 2016.

GELINSKI, C. R. O. G.; SEIBEL, E. J. Formulação de políticas públicas: questões metodológicas relevantes. Revista de Ciências Humanas, Florianópolis, v. 42, n. 1-2, p. 227-240, 2008. 
KINGSMILL, B; QUIRK, B. Foreword. In: DESING COMISSION. Restarting Britain 2: design and public services. Londres: Policy Connect, 2013. p. 5.

MAGALHÃES, T. G.; SOUZA, V. B. Controle social no Conselho Municipal do Idoso de Florianópolis: uma análise a partir dos modelos de administração pública, dos modelos de coprodução dos serviços públicos e dos modos de gestão estratégica e social. Revista de Ciências da Administração, Florianópolis, v. 17, n. especial, p. 149-164, 2015.

MALAQUIAS, J. F. et al. O controle social à luz da gestão social: a análise do COMUDE de São Valério do Sul/RS. In: SEMINÁRIO DE INICIAÇÃO CIENTíFICA, 24, 2016, Anais... Panambi: Unujuí, p. 1-8, 2016.

MILANI, C. R. S. O princípio da participação social na gestão de políticas públicas locais: uma análise de experiências latino-americanas e europeias. Revista de Administração Pública, Rio de Janeiro, v. 42, n. 3, p. 551-579, 2008.

PAULA de, H. C. et al. Mecanismos de controle social em uma capital da região metropolitana da região sudeste: iniciativas, normatização e perspectivas. In: CONGRESSO CONSAD DE GESTÃO PÚBLICA, 8, 2015. Anais... Brasília, 2015. Disponível em: < http://banco.consad.org.br/handle/123456789/1278> Acesso em 04/06/2017.

PAVIANI, N. M. S.; FONTANA, N. M. Oficinas pedagógicas: relato de uma experiência. Revista Conjectura, v. 14, n. 2, 2009.

PESTOFF, $V$. Innovations in public services: co-production and new public governance in Europe. In: BOTERO, A; PATERSON, A. G.; SAAD-SULONEN, J. (eds.) Towards peer production in public services: cases from Finland. Aalto University: Helsinki, 2012. p. 13-33.

POZATTI, M.; BERNARDES, M. M. S.; VAN DER LINDEN, J. C. S. Avaliação de soluções geradas a partir de métodos de design voltados para a inovação. Design e Tecnologia, [S.I.], v. 6, n. 12, p. 31-43, 2016.

RAMOS, M. F. et al. Conselhos setoriais: perfil dos conselheiros e sua influência na tomada de decisão. Revista Saúde e Sociedade, São Paulo, v. 21, n. 3, p. 61-70, 2012.

RUA, M. G. Políticas Públicas. Florianópolis: Departamento de Ciências da Administração/UFSC; [Brasília]: Capes: UAB, 2009. 130 p.

SOUZA, C. Políticas públicas: uma revisão da literatura. Sociologias, Porto Alegre, n.8, p. 20-45, 2006. Disponível em: <http://www.scielo.br/pdf/soc/n16/a03n16>. Acesso em 22/08/2016

SOUZA, W. F. P. As relações empresariais contemporâneas e a efetivação dos direitos fundamentais do idoso sob o foco da análise econômica do direito. Revista de Direitos Fundamentais nas Relações do Trabalho, Sociais e Empresariais, São Paulo, v. 1, n. 2, p. 321-342, 2015.

TATAGIBA, L. Conselhos gestores de políticas públicas e democracia participativa: aprofundando - debate. Revista de Sociologia e Política, Curitiba, n. 25, 2005. Disponível em: <http://www.scielo.br/scielo.php?pid=S0104-44782005000200017\&script=sci_arttext> Acesso em 23 de agosto de 2016.

TAVARES, M. C. B.; MARTINS, P. E. M.; FIGUEIREDO, V. D. Controle social no Brasil: a administração política como transformadora da percepção do gestor público na sua relação com 


\section{Artigo Completo}

a sociedade. Revista Brasileira de Administração Política. Salvador, v. 6, n. 2, p. 165-186, 2013

TORRENS, A. C. Poder legislativo e políticas públicas: uma abordagem preliminar. Revista de Informação Legislativa, Brasília, v. 50, n. 197, p.189-204, 2013.

VELASQUES, T. S.; FRANZATO, C.; DEL GAUDIO, C. Ecossistemas criativos: relações colaborativas e ação projetual nos coletivos criativos informais. International Journal of Knowledge Engineering and Management, Florianópolis, v. 4, n. 10, p. 89-106, 2015. 